\title{
Clinical Pearl: A Day in the Life: A Preemie Experience
}

Catherine Ney, MS, CCLS, Joseph R. Hageman, MD

"Have you, as a clinician, wondered what it is really like to be a premature infant being admitted to the Neonatal Intensive Care Unit? Even after spending time as a patient in the intensive care unit after a cardiac arrest, intubated, then post-operatively following a four-vessel bypass as I did in 2013, I do not think I really know what it is like for a preemie."

Have you, as a clinician, wondered what it is really like to be a premature infant being admitted to the Neonatal Intensive Care Unit? Even after spending time as a patient in the intensive care unit after a cardiac arrest, intubated, then post-operatively following a four-vessel bypass as I did in 2013 , I do not think I really know what it is like for a preemie.

Catherine Ney, my co-author, and colleagues in the Developmental Care Committee have organized an excellent simulation for NICU nurses, neonatal and pediatric nurse practitioners, residents, fellows, and faculty with help from the experts in our Simulation Unit at the University of Chicago. The simulation explores aspects of an admission experience includes admission procedures highlighting the effects of the sensory experience (i.e., sound, noise, taste, smell, light, and positioning). Additional components to effectively simulate the neonate's experience included the sensation of a weighted positioner on your chest and movement restrictions due to an overly tight swaddle and poor positioning. One of the adults assumes the role of the patient as the providers complete admission tasks with a follow-up discussion regarding the effects on development, potential pathological effects, and how it must feel for the baby.

A comprehensive introduction, led by our Neonatal Nurse Practitioner Chris Elsen, highlights premature development through a developmental care lens that helps focus our participants before their breakout simulation sessions $(1,2,3)$.

Pat Byrnes-Bowen, our physical therapist, explains the stages of development in utero and, as a consequence of preterm birth, what that infant will no longer have an opportunity to experience. As providers in this space, she discusses how we can use various tools and techniques to make the infant's extrauterine life as physically supportive as possible. Pat explains how positioning needs change and how important proper positioning can be to aiding in a successful life as a young child and adult.

Moving through our additional stations, participants discuss taste and smell with Julie Sadowski, Speech-Language Pathologist, and myself (Dr. H). In this session, participants learn about the aspects of development in utero that prepare infants for feeding later and how exposure to noxious smells can interfere with bonding and deter patient's from positive oral experiences. This simulation allows participants to smell common items used on or near these patients at a high concentration. They are encouraged to smell various containers and identify alcohol wipes, adhesive remover, and perfume. Even in the age of mask-wearing, these smells permeate without losing their potency $(6,7)$.

\section{"As the participants digest these thoughts, the lights are dimmed, and they are encouraged to get comfortable in their chairs with eyes closed as they are about to enter the world of a preemie for a few moments. Recorded sounds are played, starting with a heartbeat track that is layered with common noises on the unit. Participants appear visibly shocked as these noises begin and have thoughtful comments during our discussion"}

As participants enter the sound and vision station, they often notice an iPad set up with a decibel reader that is left on throughout the discussion. Catherine walks them through the developmental components of life in utero and the fascinating way the evolution of pregnancy prepares infants for the outside world. For most of our patient population, this natural experience is stripped away as they are thrust into a space that assaults their immature sensory systems. As the discussion moves toward sound, graphs are highlighted with decibel level readings of physical spaces on our unit compared to the recommended level of $45 \mathrm{~dB}$ 's. The discussion in the room spikes to the mid $70 \mathrm{~dB}$ range with just one person talking (8-11). As the participants digest these thoughts, the lights are dimmed, and they are encouraged to get comfortable in their chairs with eyes closed as they are about to enter the world of a preemie for a few moments. Recorded sounds are played, starting with a heartbeat track that is layered with common noises on the unit. Participants appear visibly shocked as these noises begin and have thoughtful comments during our discussion.

Prior to the final discussion, all participants are gathered for a presentation on mindfulness. Working in the health care field and in an intensive care unit demands more than clinical competence. Compassionate care supports a family-centered model but can be hard to sustain amid the daily challenges on our unit, not to mention the global pandemic. Participants are encouraged to explore the use of G.R.A.C.E. to help support their cultivation of compassionate care toward their patients and families and find ways to support their capacity to do so (12). . 
We also discuss what the clinicians can do to be more sensitive to the infant's senses and developmental needs, optimize their NICU experience, and minimize the negative effects of this experience.

\section{"We have a debrief and ask them what can be done to improve the experience and have received a lot of helpful feedback to refine the simulation."}

We have had several nurses, NNPs, fellows, and attending neonatologists experience this simulation, and the feedback has been really positive thus far. We have a debrief and ask them what can be done to improve the experience and have received a lot of helpful feedback to refine the simulation.

This is by no means a unique simulation as other NICUs have been doing this for a number of years (Phillips https://www.learningconnection.philips.com/en/course/preemie-day), and Catherine has spoken with clinicians from other units about their programs.

We will continue to refine this Day in the Life simulation and plan to do some follow-up surveys for those clinicians who have been through this to see if it has affected their practice in the NICU. An educational handout with summaries of development and the senses is also provided (Appendix 1) for the attendees.

"We will continue to refine this Day in the Life simulation and plan to do some follow-up surveys for those clinicians who have been through this to see if it has affected their practice in the NICU. An educational handout with summaries of development and the senses is also provided (Appendix 1) for the attendees."

\section{References}

1. Als, H. "Newborn individualized developmental care and assessment program (NIDCAP): new frontier for neonatal and perinatal medicine. " Journal of Neonatal-Perinatal Medicine 2.3 (2009): 135-147.

2. Liu, W. F., Laudert S, Perkins B et al. et al. "The development of potentially better practices to support the neurodevelopment of infants in the NICU." Journal of Perinatology 2007; 27.S2: S48-S74.

3. Coughlin, M, Gibbins S, Hoath $S$. "Core measures for developmentally supportive care in neonatal intensive care units: theory, precedence and practice." Journal of advanced nursing 2009: 65(10): 2239-2248.
4. Chizawsky, LLK, Scott $\square$ Findlay S. "Tummy Time!." Nursing for Women's Health 2005; 9(5): 382-387.

5. Browne, J. Chemosensory development in the fetus and newborn. Newborn and infant nursing reviews. 2008; 8:4.

6. Bloomfield, F., Alexander, T.,Muelbert M, et al. . Smell and taste in the preterm infant. Early Human Development, 2017; 114: 31-34.

7. Beker, F., Opie, G., Jiang $Y$ et al. .Smell and taste to improve nutrition in very preterm infants: A randomized controlled pilot trial. Neonatology 2017; 111: 260-266.

8. Casavant, S., Bernier, K. Andrews S, Bourgoin A., Noise in the neonatal intensive care unit. Advances in Neonatal Care 2017; 17(4), 265-273

9. Ahamed, M., Campbell, D., Horan S, Rosen O.. Noise reduction in the neonatal intensive care unit: a quality improvement initiative. American Journal of Medical Quality 2018; 33(2), $177-184$.

10. Almadhoob, A. \& Ohlsson, A.). Sound reduction management in the neonatal intensive care unit for preterm or very low birthweight infants. Cochrane Database of Systemic Reviews 2015; (1), 1-30.

11. Sprouse, B. (2017). NICU Noise Levels [PowerPoint Slides]. Retrieved from file:///G:/April\%202017--UCM\%20NICU\%20 NOISE.pdf

12. Halifax, Joan. (2013). G.R.A.C.E. for nurses: Cultivating compassion in nurse/patient interactions. Journal of Nursing Education and Practice. 4. 10.5430/jnep.v4n1p121.

Disclosures: The authors have no conflicts to disclose

NT

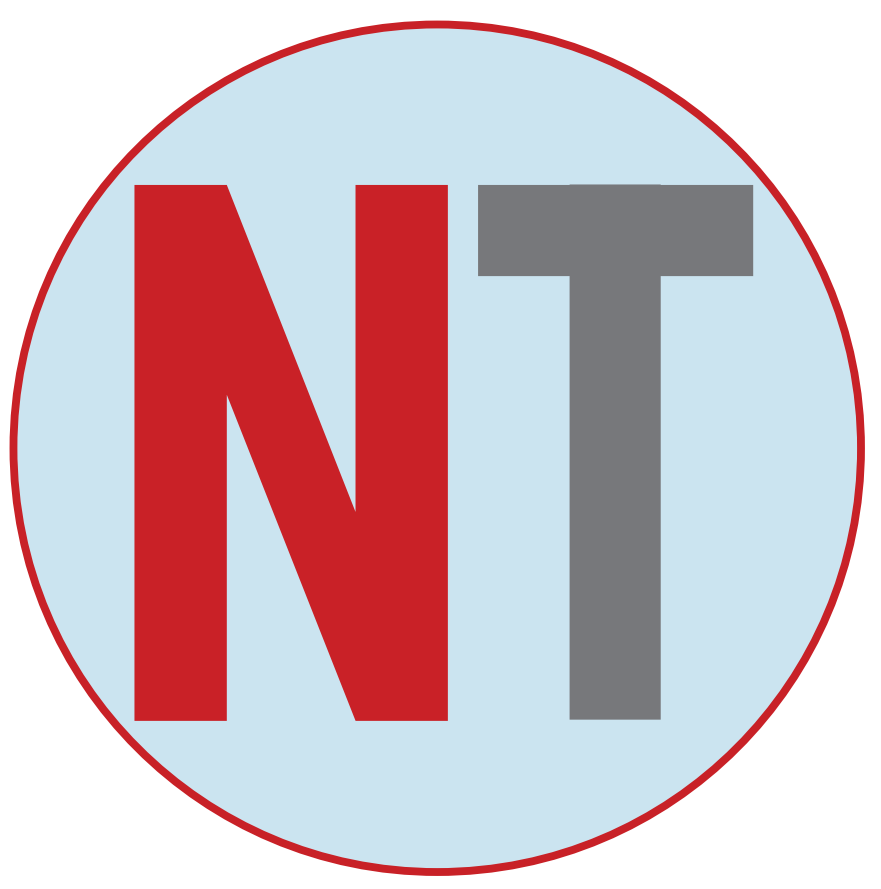

NEONATOLOGY TODAY is interested in publishing manuscripts from Neonatologists, Fellows, NNPs and those involved in caring for neonates on case studies, research results, hospital news, meeting announcements, and other pertinent topics. Please submit your manuscript to: LomaLindaPublishingCompany@gmail.com 


\section{A Day in the Life: \\ A Preemie Experience Educational Handout}

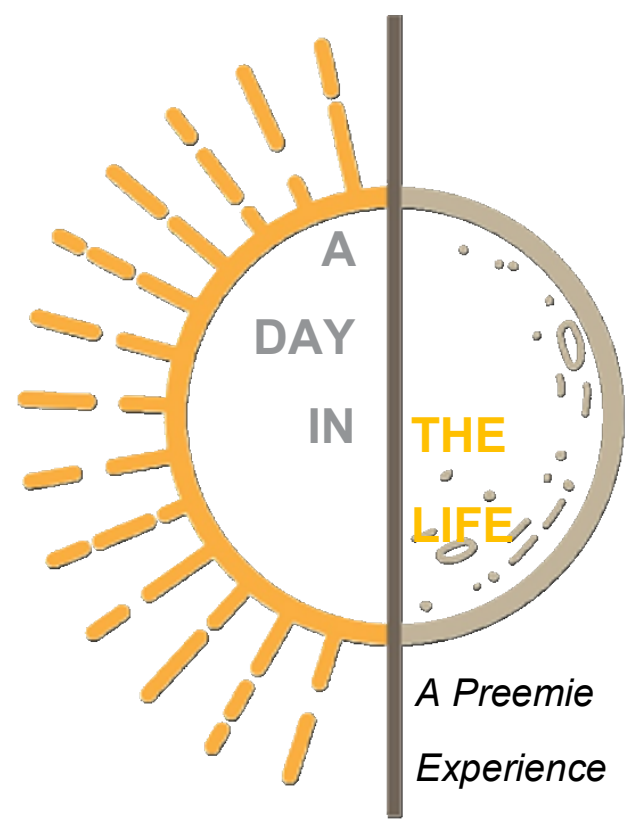




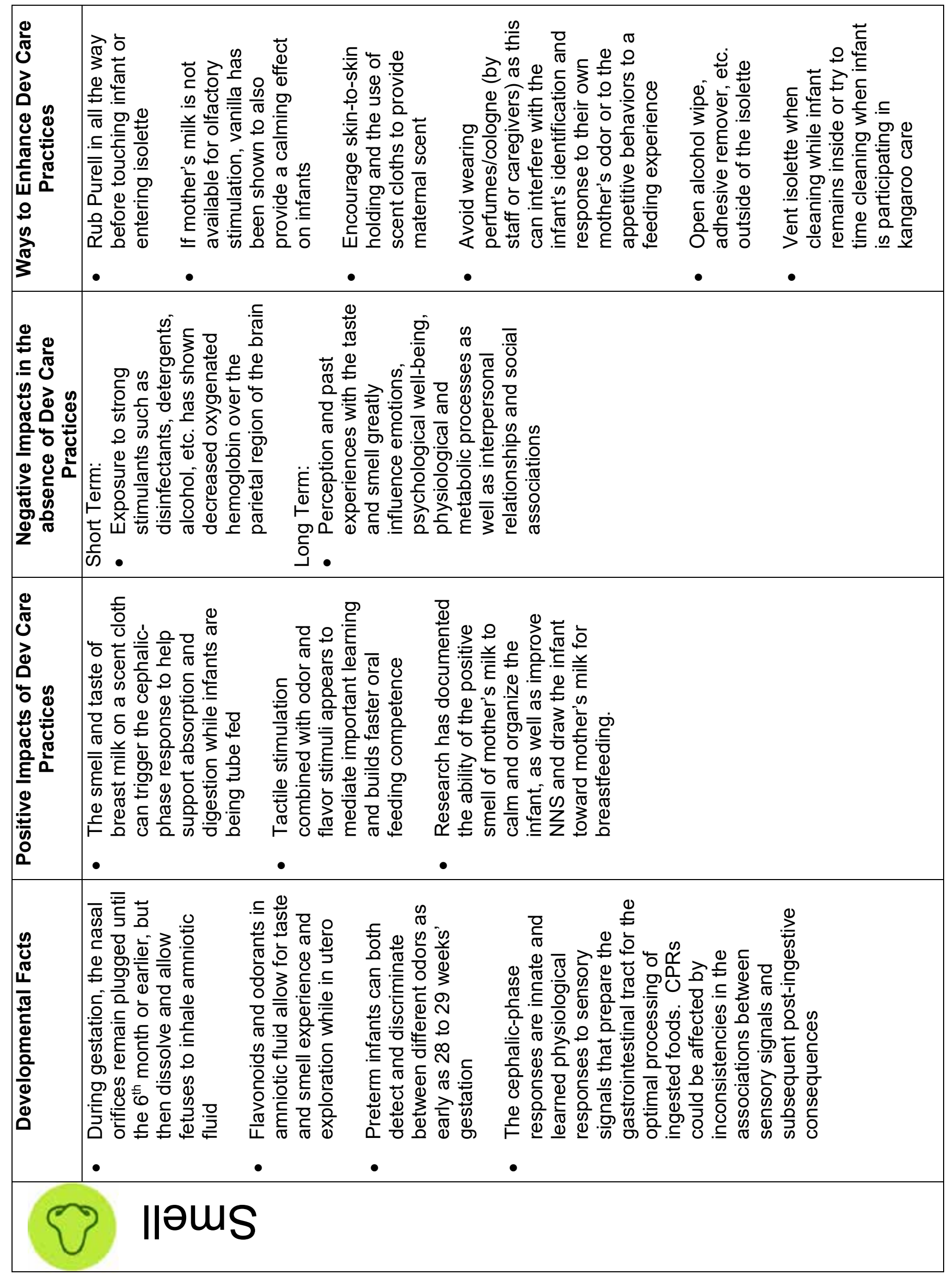




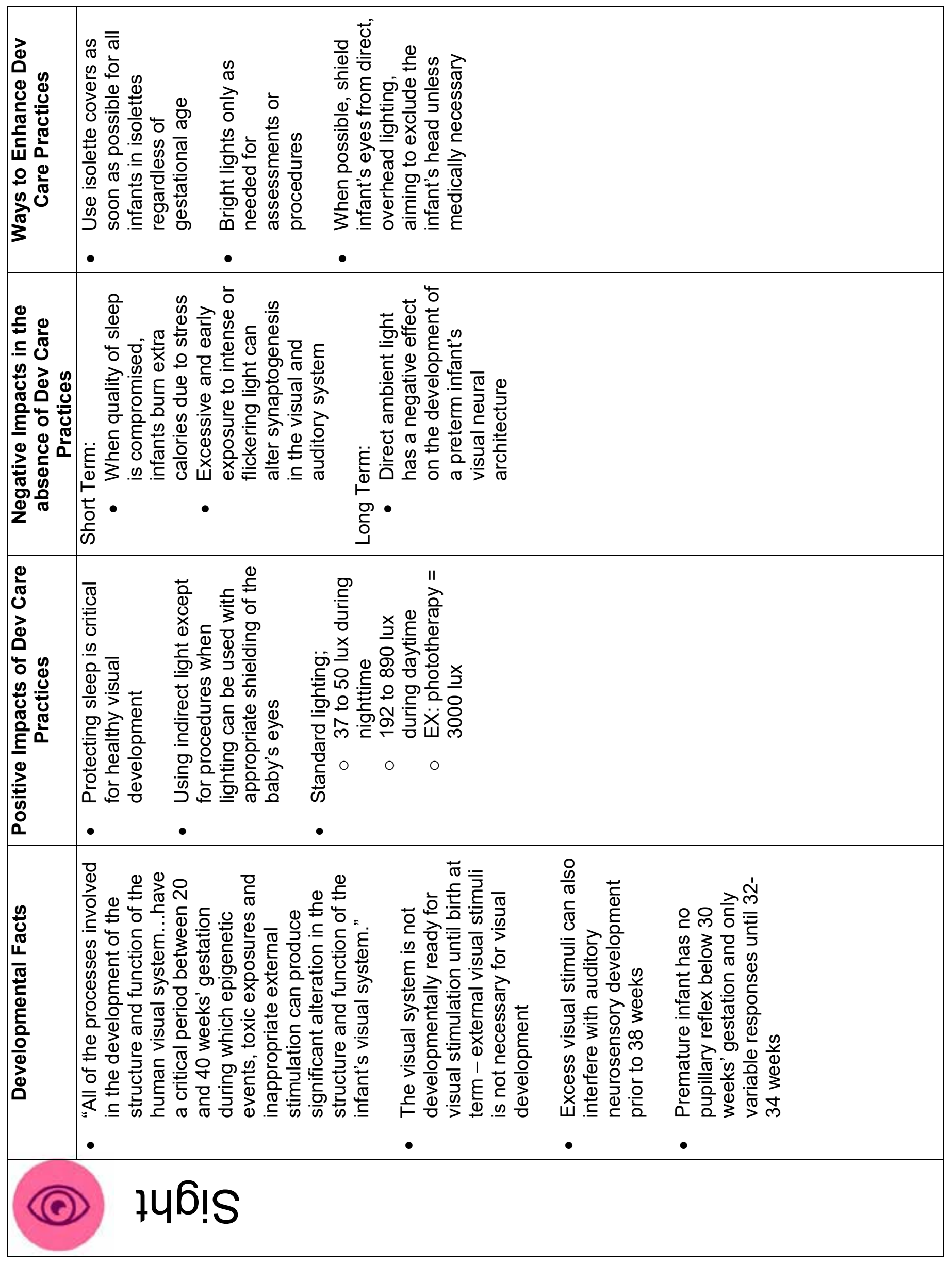




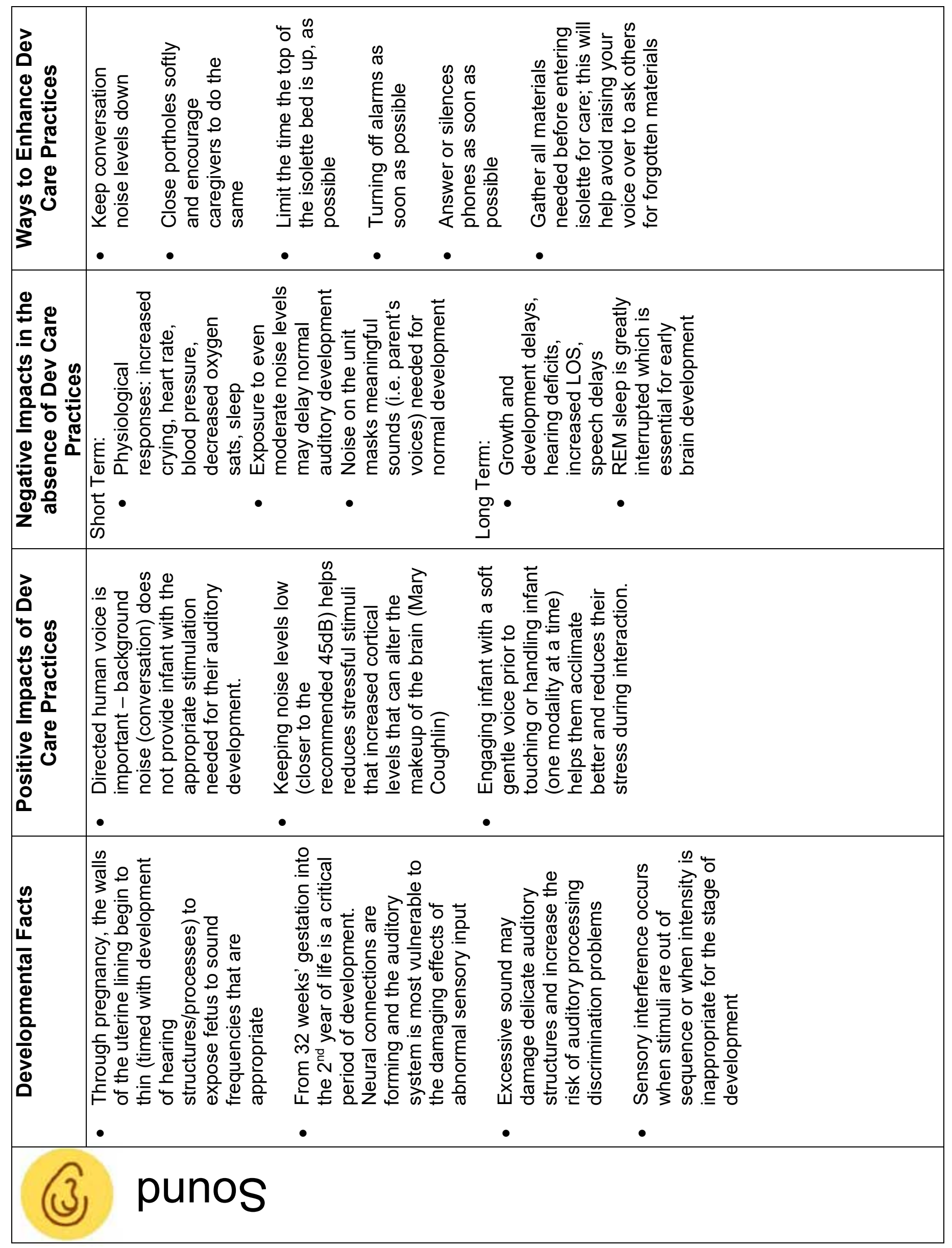




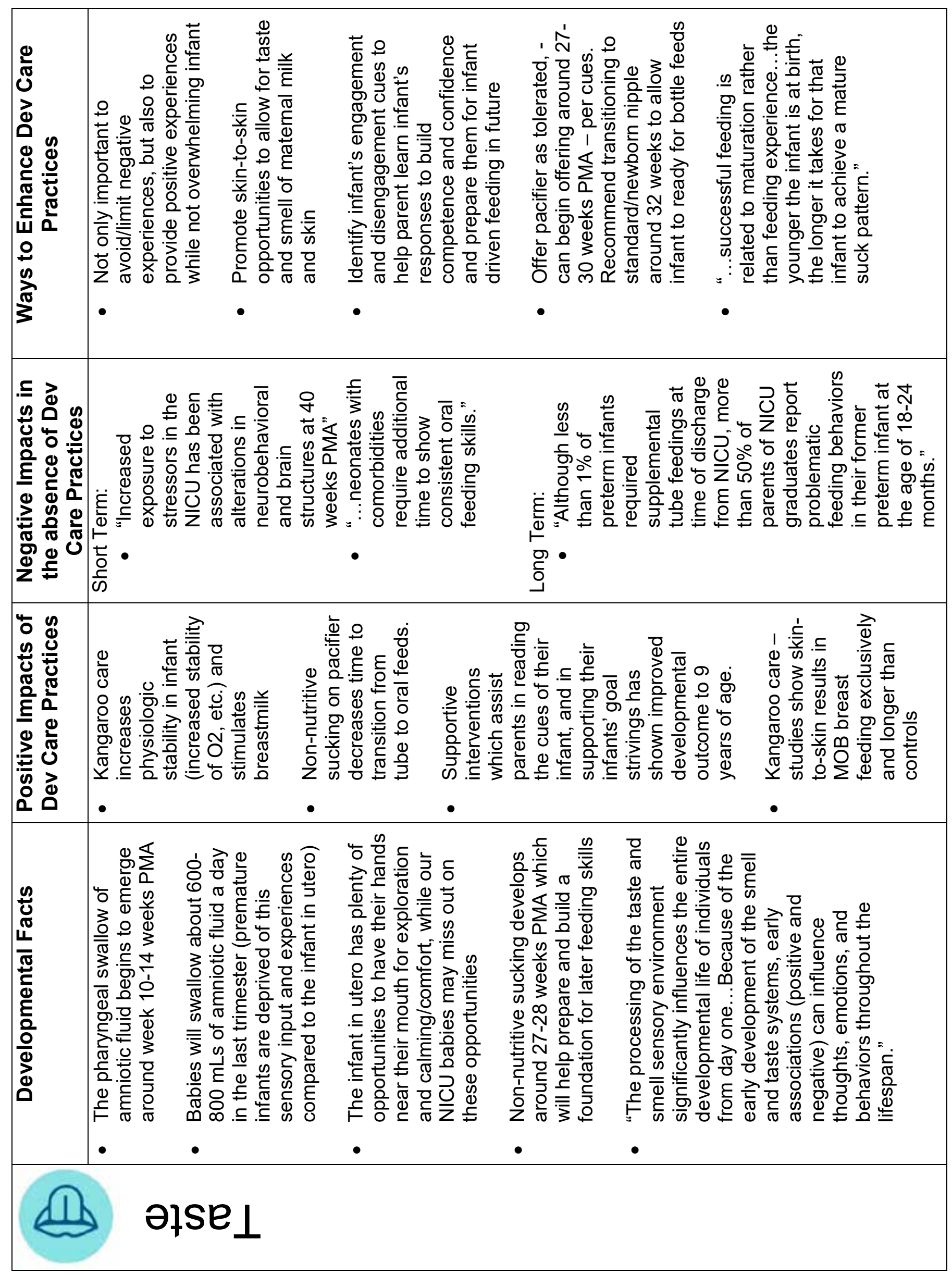




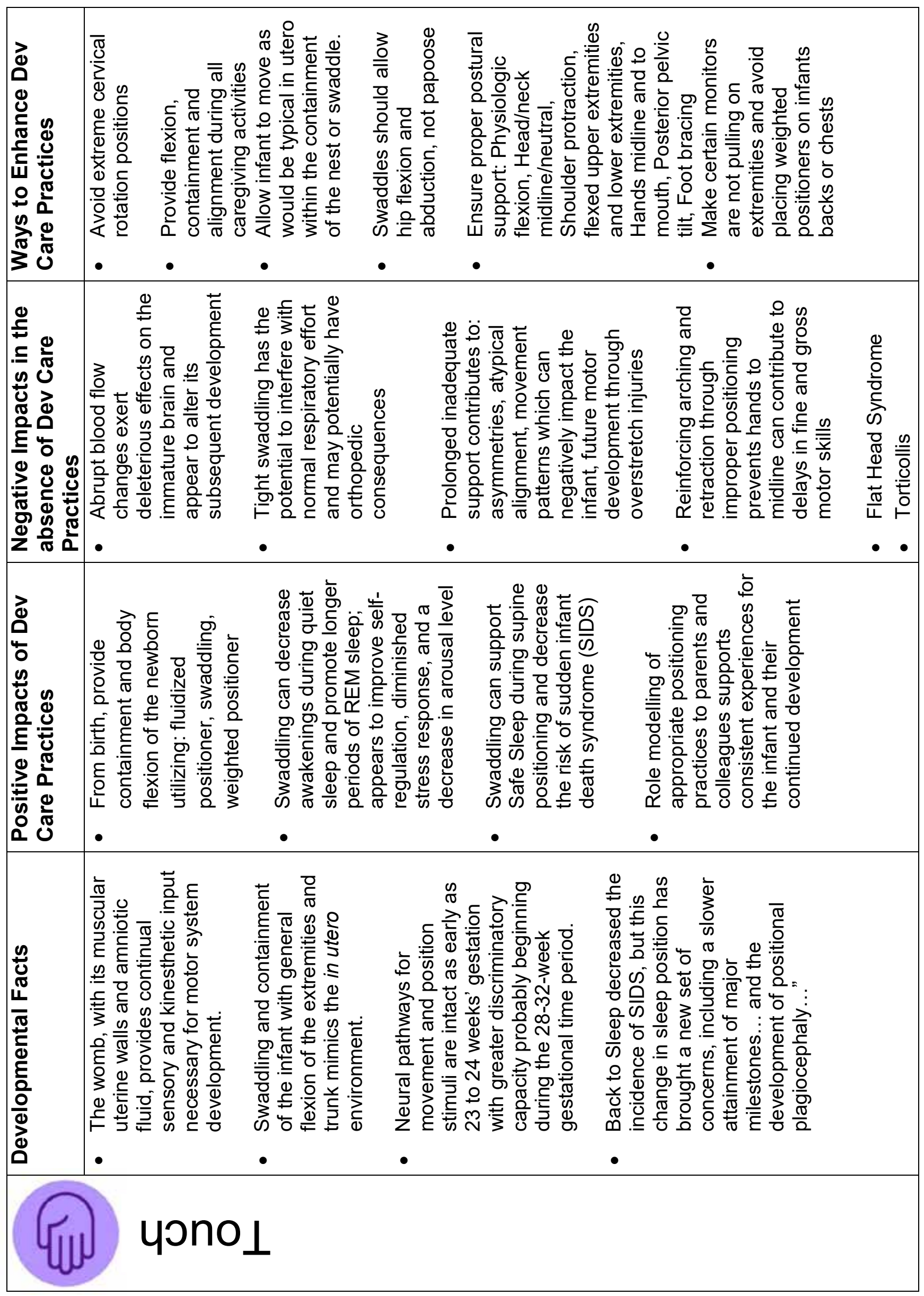




\section{ChildKind Tips}

On our journey to ChildKind, here is are tips for easing pain

\section{and promoting comfort based on the senses:}

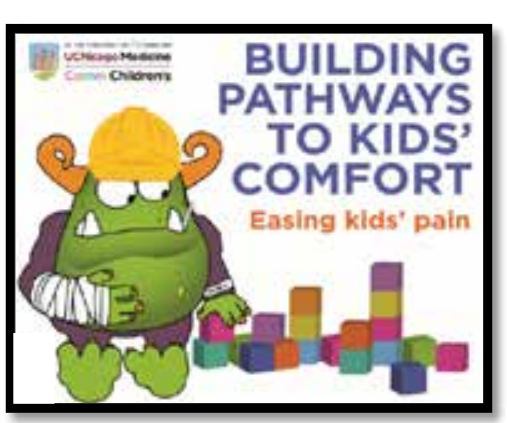

Q

Providing mother's odor during invasive procedures (i.e. heel sticks) in infants has been shown to reduce reactivity and shorten the return to baseline.

Try to use bright lights as little as possible and use an eye shield or cloth to cover infant's eyes.

Decreasing unnecessary background noises and volume (i.e. conversations, alarms, doors) allows for increased opportunities for babies to experience positive auditory input through human voice (i.e. reading or talking softly at bedside).

Avoid frequent taping/re-taping around mouth and nose and try to transition from OG to NG, as able, to reduce negative oral sensory experiences.

Providing swaddling support on non-affected limbs during painful procedures like IV starts can help reduce stress, minimize physiological responses and help infant return to baseline quicker following procedure. 

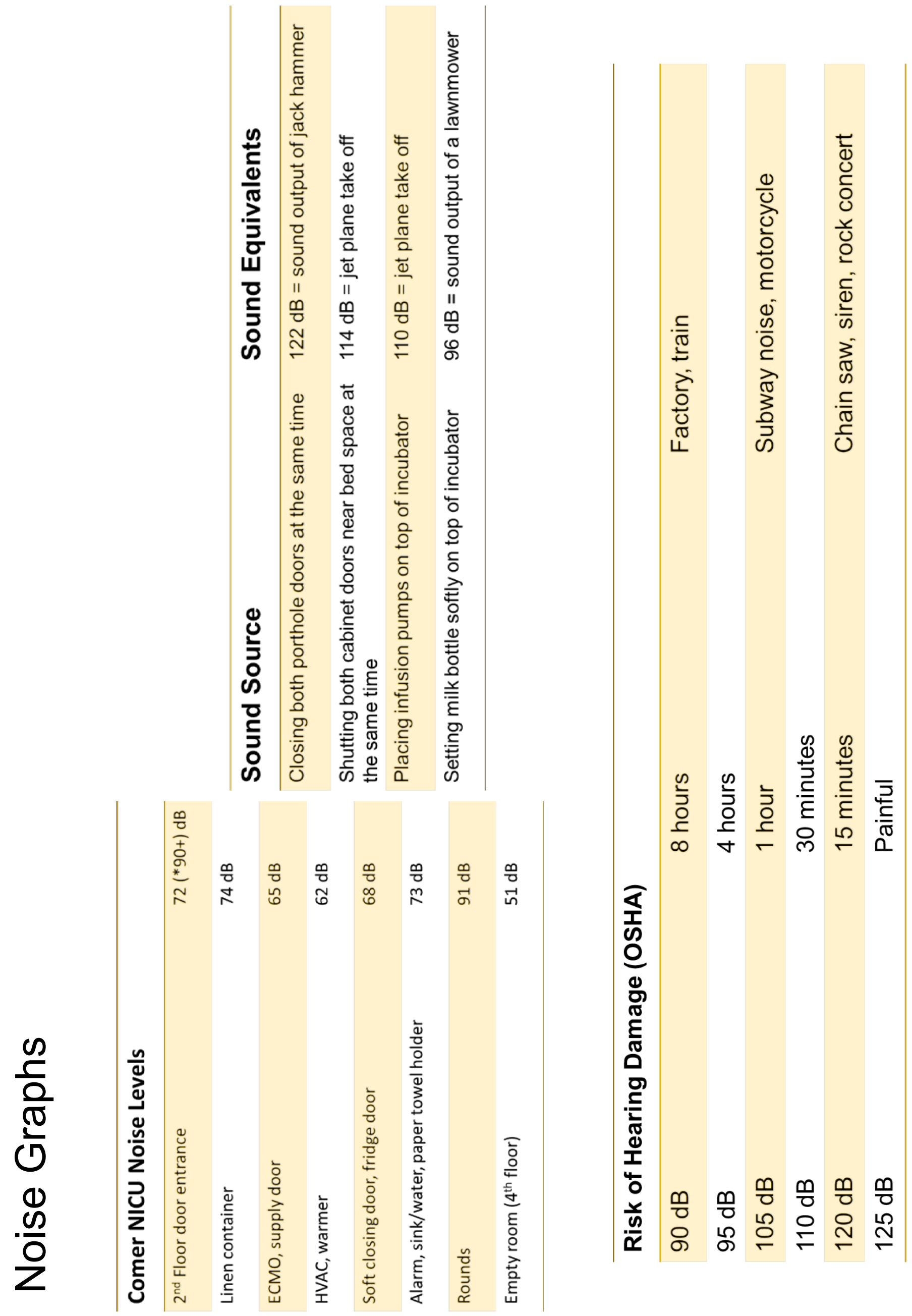

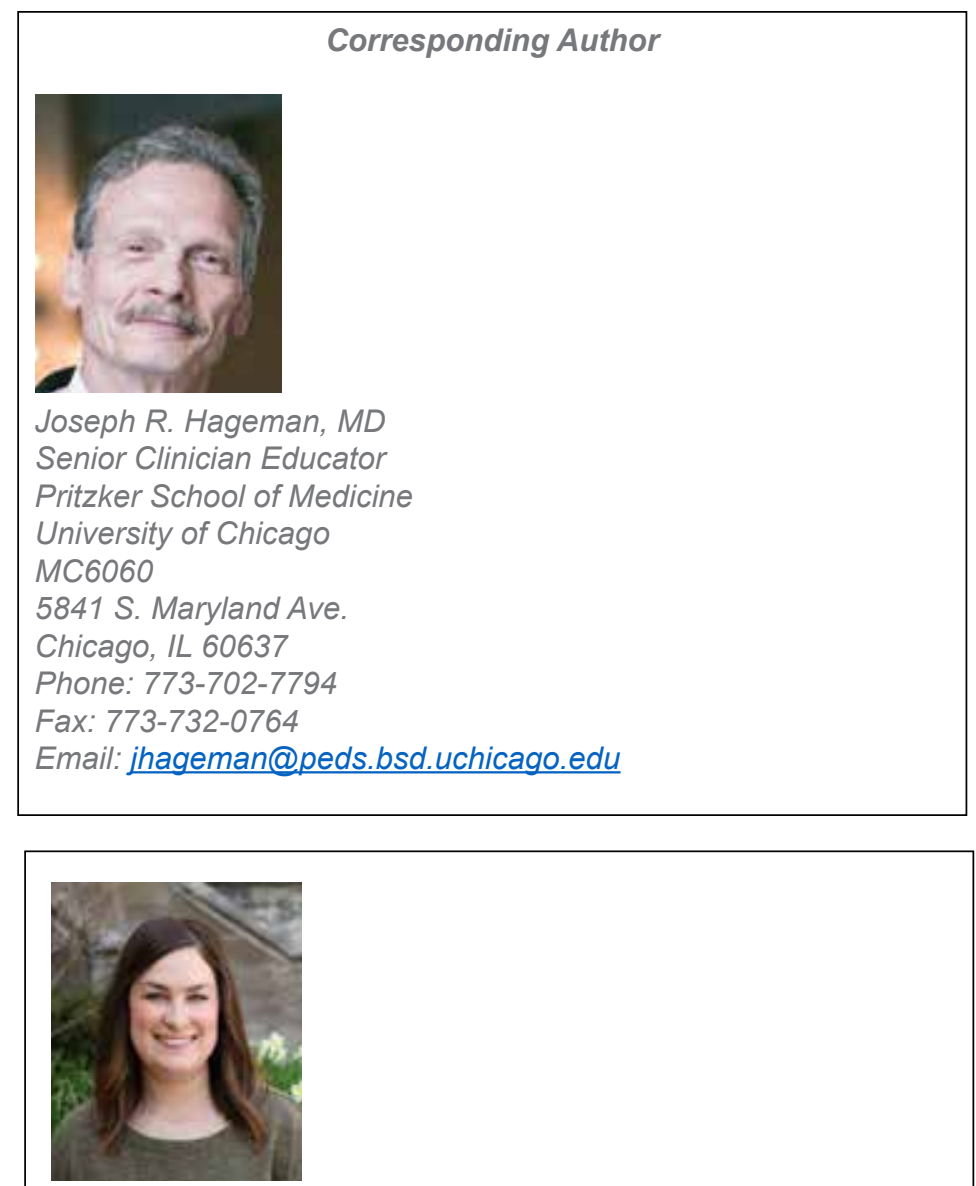

Catherine Ney, MS, CCLS

Child Life Specialist I

The University of Chicago Medicine

5721 S. Maryland Ave. | Rm. K135, MC8008 | Chicago, IL 60637 Office: 773-795-5120

Email: Catherine.Ney@uchospitals.edu

Clinical Pearls are published monthly.

Submission guidelines for "Clinical Pearls":

1250 word limit not including references or title page.

May begin with a brief case summary or example.

Summarize the pearl for emphasis.

No more than 7 references.

Please send your submissions to:

jhageman@peds.bsd.uchicago.edu

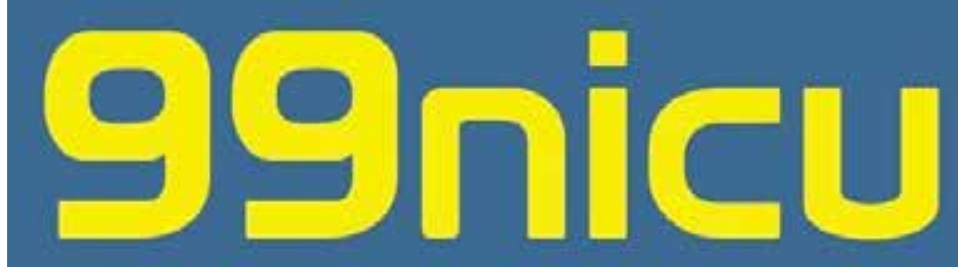

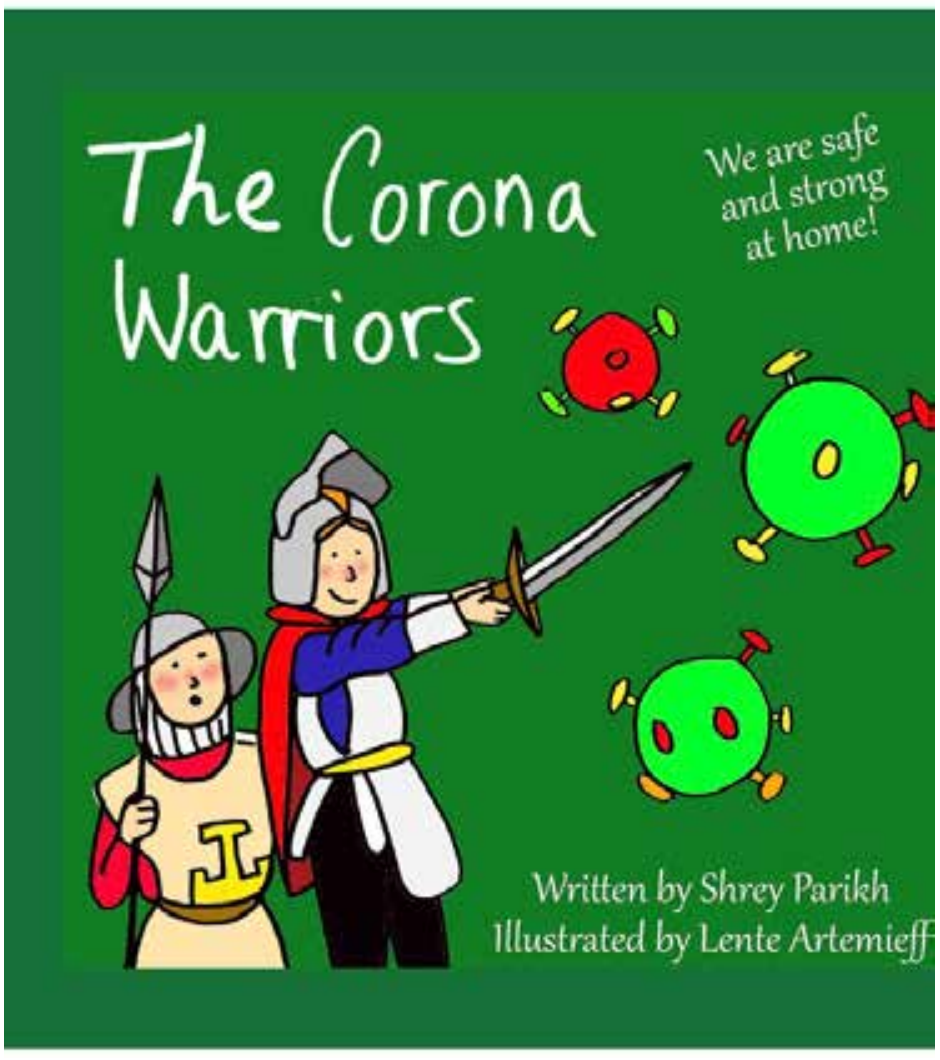

\section{Oo National Perinatal Association PERINATAL MENTAL HEALTH}

nationalperinatal.org/position

www.nationalperinatal.org/mental_health

\section{SCREEN \\ DADS TOO \\ $10 \%$ of fathers \\ experience depression \\ and anxiety during \\ the perinatal period}

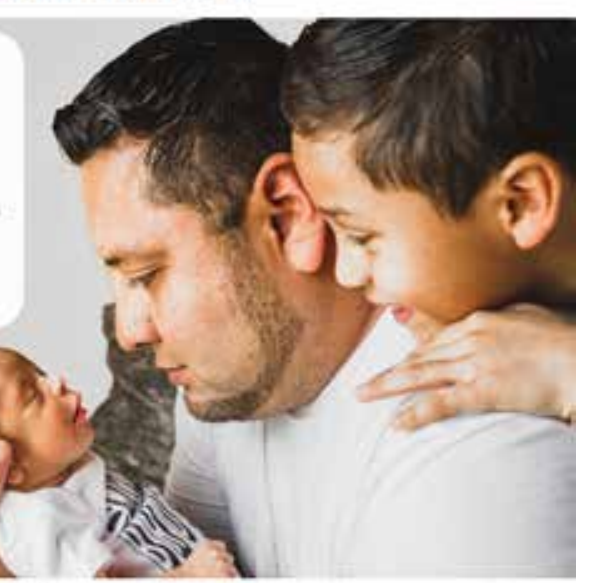

Educate. Advocate. Integrate.

Sign up for free membership at 99nicu, the Internet community for professionals in neonatal medicine. Discussion Forums, Image Library, Virtual NICU, and more..."

\section{www. 99 nicu. org}

